Appl. Ent. Zool. 23 (2): 144-149 (1988)

\title{
Contribution of Recessive Factor on the Third Chromosome to Pyrethroid-Resistance in Houseflies, Musca domestica L. (Diptera: Muscidae)
}

\author{
Yoji TaKada, Masachika Hirano and Toshiki Hiroyoshi ${ }^{1}$ \\ Pesticide Research Laboratory, Takarazuka Research Center, \\ Sumitomo Chemical Co., Ltd., Takarazuka, Hyogo 665, Japan \\ ${ }^{1}$ Department of Genetics, Medical School, Osaka University, \\ Kita-ku, Osaka 530, Japan
}

(Received August 26, 1987)

\begin{abstract}
We investigated the contribution of the recessive factor on the third chromosone to the pyrethroid-resistance in $228_{\mathrm{e} 2 \mathrm{~b}}$ strain and in Miyakonojo colony of houseflies using " $B x^{2}$ " gene. In the $228_{\mathrm{e} 2 \mathrm{~b}}$ strain, the resistance to permethrin and fenvalerate is associated with the recessive factor on the third chromosome. The contribution of the recessive factor on the third chromosome in the Miyakonojo colony, however, was undetectable. Furthermore, the resistance factor on the third chromosome in the $228_{\mathrm{e}} \mathrm{b}$ strain influenced not only the mortality but also the knockdown time. The genetic method used in this study is considered very simple and useful to learn the importance of the recessive resistance factor on the third chromosome.
\end{abstract}

\section{INTRODUCTION}

It is known that the $228_{\mathrm{e} 2 \mathrm{~b}}$ strain of the housefly from Denmark has a major recessive resistance factor associated with nerve insensitivity for permethrin on the third chromosome, and that no other factors are found (AHN et al., $1986 \mathrm{a}, \mathrm{b}$ ). We found that factors conferring resistance in the Miyakonojo colony with selection by permethrin existed on autosomes 2, 3 and 5 (TAKADA et al., 1988).

In this study, we compared the contribution of the recessive factor on the third chromosome to pyrethroid-resistance in $228_{\mathrm{e} 2 \mathrm{~b}}$ strain and in Miyakonojo colony without selection using the dominance marker " $B x^{2}$ " on the third chromosome.

\section{MATERIALS AND METHODS}

Housefies. The following strains and colony of houseflies (Musca domestica L.) were used. The miyakonojo colony was collected in Miyakonojo, Miyazaki Prefecture, Japan, in 1983 (HAYASH et al., in preparation), and showed moderate resistance to both pyrethroids and organophosphates. The $228_{\mathrm{e} 2 \mathrm{~b}}$ strain obtained from Dr. J. KeIDING is a strain resistant to pyrethroids (KeIDING, 1976). The susceptible $B x^{2}$ strain has one dominant marker on the third chromosome. The wing is snipped from various directions and its phenotype is shown in Fig. 1. The homozygote of the gene is lethal. Viability of the heterozygote is about 50 percent that of the wild type (Hrro- 

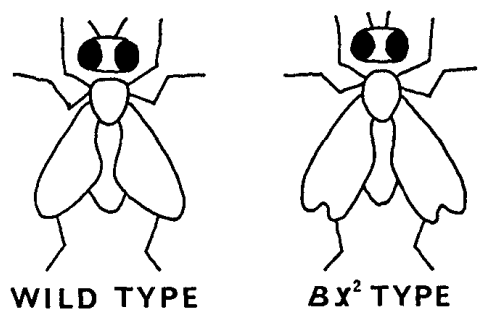

Fig. 1. The phenotype of $B x^{2}$ strain of houseflies. In $B x^{2}$ type, the wing is snipped from several directions. Homozygotic lethal character.
Resistant strain or colony 우 $\times B x^{2}$ strain $\hat{\delta}$

$(+1+) \quad \downarrow \quad\left(+\mid B x^{2}\right)$

$\mathrm{F}_{1}$ progeny $(+\mid+)$ or $\quad\left(+\mid B x^{2}\right)$

Resistant strain or colony $q \times F_{1}$ progeny $\hat{\delta}$

\begin{tabular}{c|c}
$(+\mid+)$ & \\
Backcrossed progeny $(+\mid+)$ or & $\left(+\mid B x^{2}\right)$
\end{tabular}

Fig. 2. Scheme of crosses used to investigate the contribution of the recessive resistance factor on the third chromosome.

Yoshi, 1977). A susceptible CSMA strain was obtained from Dr. O. F. BodensteIn, USDA in 1974.

Chemicals. The insecticides used and their purities are as follows: permethrin : 3phenoxybenzyl (1RS)-cis, trans-3-(2,2-dichlorovinyl)-2,2-dimethylcyclopropanecarboxylate $(91.8 \%)$, fenvalerate : $(R S)$ - $\alpha$-cyano-3-phenoxybenzyl $(R S)$-2-(4-chlorophenyl)-3methylbutyrate $(94.2 \%)$, tetramethrin : 3,4,5,6-tetrahydrophthalimidomethyl $(1 R S)$ cis,trans-chrysanthemate $(94.2 \%)$, fenitrothion : O,O-dimethyl O-p-nitro- $m$-tolyl phosphorothioate $(96.7 \%)$.

Toxicity test. Topical application method: The appropriate dosages of test chemicals in $0.5 \mu \mathrm{l}$ of acetone were applied topically to the thoracic dorsa of four-day old female adult flies. Acetone was applied to control flies. Each assay was replicated twice, using 30 flies per replicate. Treated flies were kept at $26 \pm 1^{\circ} \mathrm{C}$ and mortalities were determined $24 \mathrm{hr}$ after treatment.

Oil spray method: After 20 female adult flies four-day old were released into a glass chamber $\left(0.34 \mathrm{~m}^{3}\right), 0.7 \mathrm{ml}$ of predetermined concentrations of a test chemical in oil formulation was sprayed into the chamber with a spray gun at a pressure of $0.8 \mathrm{~kg} / \mathrm{cm}^{2}$. Records of knockdown were made at various intervals up to $15 \mathrm{~min}$ and thereafter all the insects tested were collected and transferred into a recovery container to observe the mortality after $24 \mathrm{hr}$.

Analysis of recessive resistant factor on the third chromosome. By the backcross method using $F_{1}$ males, the recessive resistant factor for an insecticide was investigated on the third chromosome in houseflies. The males of $B x^{2}$ strain $\left(+\mid B x^{2}\right)$ were crossed to the females of the resistant strain or colony in mass, and then $F_{1}$ males $\left(+\mid B x^{2}\right)$ were backcrossed to the females of the resistant strain or colony in mass (Fig. 2). In order to obtain virgin females, adults were isolated within $4 \mathrm{hr}$ of emergence.

Degree of dominance. The degree of dominance (D) of resistance in hybrids between the susceptible and resistant houseflies was calculated by the method of STONE (1968) and Georghiou (1969). $\quad D=\left(2 X_{2}-X_{1}-X_{3}\right) /\left(X_{1}-X_{3}\right)$, where $X_{1}, X_{2}$ and $X_{3}$ represent the $\mathrm{LD}_{50}$ values of the resistant, $F_{1}$ hybrid and susceptible houseflies respectively.

\section{RESULTS}

$\mathrm{LD}_{50}$ values of resistant strains as well as of the susceptible CSMA strain for three insecticides are given in Table 1 . The $228_{\mathrm{e} 2 \mathrm{~b}}$ strain possesses a high level of resistance 
Table 1. Susceptibility of $228_{\Theta 2 b}$ strain and Miyakonojo colony of the housefly to three insecticides

\begin{tabular}{lccc}
\hline & \multicolumn{3}{c}{ LD $_{50}(\mu \mathrm{g} /$ female fly $)$} \\
\cline { 2 - 4 } Insecticide & CSMA & $228_{\text {e2b }}$ & Miyakonojo \\
\hline Permethrin & 0.021 & $4.4(210)^{\mathrm{a}}$ & $0.27(13)$ \\
Fenvalerate & 0.028 & $20(710)$ & $0.40(14)$ \\
Fenitrothion & 0.064 & $1.1(17)$ & $2.0(31)$ \\
\hline
\end{tabular}

a Resistance factor $=\frac{\mathrm{LD}_{50} \text { value of resistance } f l y}{\mathrm{LD}_{50} \text { value of CSMA strain }}$.

Table 2. Susceptibility of $228_{\mathrm{e}} \mathrm{b}$ strain and Miyakonojo colony of housefly to pyrethroids $(1 \%$ oil spray method)

\begin{tabular}{|c|c|c|c|c|}
\hline \multirow{2}{*}{ Insecticide } & \multicolumn{2}{|c|}{$\mathrm{KT}_{50}(\mathrm{~min})$} & \multicolumn{2}{|c|}{ Mortality $(\%)^{a}$} \\
\hline & $228_{\ominus 2 b}$ & Miyakonojo & $228_{\mathrm{e} 2 \mathrm{~b}}$ & Miyakonojo \\
\hline Permethrin & $>15$ & 5.9 & 15.0 & 100 \\
\hline Fenvalerate & 13 & 7.2 & 22.5 & 92.5 \\
\hline Tetramethrin & 10 & 1.6 & 0 & 7.5 \\
\hline
\end{tabular}

a Mortality after $24 \mathrm{hr}$ for all houseflies tested.

Table 3. Susceptibility of $B x^{2}$ strain of housefly to insecticides

\begin{tabular}{ccc}
\hline Insecticide & $\begin{array}{c}\text { Genotype of } \\
\text { III chromosome }\end{array}$ & $\begin{array}{c}\mathrm{LD}_{50}(\mu \mathrm{g} / \mathrm{female} \text { fly }) \\
(95 \% \text { C.L. })\end{array}$ \\
\hline Permethrin & $+/+$ & $0.018(0.016-0.020)$ \\
& $+/ B x^{2}$ & $0.021(0.018-0.025)$ \\
Fenvalerate & $+/+$ & $0.037(0.031-0.043)$ \\
& $+/ B x^{2}$ & $0.041(0.032-0.047)$ \\
Fenitrothion & $+/+$ & $0.058(0.047-0.065)$ \\
& $+/ B x^{2}$ & $0.059(-)^{2}$ \\
\hline
\end{tabular}

a Not determined.

to the two pyrethroids and a moderate level of resistance to fenitrothion. On the other hand, the Miyakonojo colony shows only a moderate level of resistance to these insecticides. $\mathrm{KT}_{50}$ values and mortalities of the $228_{\mathrm{e} 2 \mathrm{~b}}$ strain and Miyakonojo colony with the three pyrethroids by $1 \%$ oil spray method are given in Table 2. In this method as well as in the topical application method, $228_{\mathrm{e} 2 \mathrm{~b}}$ strain shows a lower level of susceptibility to pyrethroids than Miyakonojo colony in both $\mathrm{KT}_{50}$ value and mortality.

Susceptibility of two genotypes in $B x^{2}$ strain of the housefly to pyrethroids was investigated by $0.1 \%$ oil spray method and topical application method (Tables 3 and 4). From these results, no difference in susceptibility between the two genotypes to the insecticides tested was observed.

Table 5 shows the susceptibility of $F_{1}$ progeny and $D$ value to permethrin. Here, it is clear that $228_{\mathrm{e} 2 \mathrm{~b}}$ strain is quite different from Miyakonojo colony in $D$ value. 
Table 4. Susceptibility of $B x^{2}$ strain of housefly to pyrethroids $(0.1 \%$ oil spray method)

\begin{tabular}{cccc}
\hline Insecticide & $\begin{array}{c}\text { Genotype of } \\
\text { III chromosome }\end{array}$ & $\begin{array}{c}\mathrm{KT}_{50} \\
(\mathrm{~min})\end{array}$ & $\begin{array}{c}\text { Mortality } \\
(\%)^{\mathrm{a}}\end{array}$ \\
\hline Permethrin & $+1+$ & 8.9 & 95.0 \\
& $+/ B x^{2}$ & 8.4 & 90.0 \\
Tetramethrin & $+/+$ & & 2.5 \\
& $+/ B x^{2}$ & 1.6 & 7.5 \\
\hline
\end{tabular}

a Mortality after $24 \mathrm{hr}$ for all houseflies tested.

Table 5. Susceptibility of $F_{1}$ progeny of housefly (resistant strain or colony $ᄋ \times B x^{2}$ strain $\left.\hat{\delta}\right)$ and $D$ value to permethrin

\begin{tabular}{ccccccc}
\hline Insecticide & $\begin{array}{c}\text { Genotype } \\
\text { of III } \\
\text { chromosome }\end{array}$ & $228_{\mathrm{e} 2 \mathrm{~b}}$ & Miyakonojo & & \multicolumn{2}{c}{$D$ value } \\
\cline { 3 - 4 } Permethrin & $+/+$ & 0.089 & 0.17 & & -0.97 & 0.21 \\
& $+/ B x^{2}$ & $(0.079-0.096)$ & $(0.14-0.19)$ & & Miyakonojo \\
& 0.091 & 0.18 & -0.97 & 0.28 \\
& $(0.080-0.11)$ & $(-)^{\mathrm{b}}$ & &
\end{tabular}

a Figures in parentheses mean $95 \%$ confidence limit.

b Not determined.

Table 6. Susceptibility of backcrossed progeny of housefly (resistant strain or colony 우 $\times \mathrm{F}_{1}$ progeny $+\left(B x^{2} \hat{\delta}\right)$ to insecticides

\begin{tabular}{|c|c|c|c|}
\hline \multirow{2}{*}{ Insecticide } & \multirow{2}{*}{$\begin{array}{c}\text { Genotype } \\
\text { of III } \\
\text { chromosome }\end{array}$} & \multicolumn{2}{|c|}{$\mathrm{LD}_{50}(\mu \mathrm{g} / \text { female fly })^{\mathrm{a}}$} \\
\hline & & $228_{\Theta 2 \mathrm{~b}}$ & Miyakonojo \\
\hline \multirow[t]{2}{*}{ Permethrin } & $+1+$ & $2.5 \quad(2.0-3.1)$ & $0.14(0.12-0.17)$ \\
\hline & $+/ B x^{2}$ & $0.14(0.13-0.16)$ & $0.13(0.12-0.15)$ \\
\hline \multirow[t]{2}{*}{ Fenvalerate } & $+1+$ & $12 \quad(9.2-19)$ & $0.32(0.27-0.38)$ \\
\hline & $+/ B x^{2}$ & $0.59(0.49-0.73)$ & $0.33(0.23-0.58)$ \\
\hline \multirow[t]{2}{*}{ Fenitrothion } & $+1+$ & $0.51(0.41-0.62)$ & $(1.4-1.9)$ \\
\hline & $+\mid B x^{2}$ & $0.59(0.43-0.69)$ & $1.6(1.4-1.8)$ \\
\hline
\end{tabular}

a Figures in parentheses mean $95 \%$ confidence limit.

$D$. value in each phenotype of the two resistant houseflies was identical in susceptibility to permethrin. Thus, the presence of polygene was not recognized. Table 6 shows the $\mathrm{LD}_{50}$ values of backcrossed progeny (resistant strain or colony $\times \mathrm{F}_{1}$ progeny). In the $228_{\text {e2b }}$ strain, a remarkable difference between $F_{2}$ progeny of the two genotypes in the $L_{50}$ values of permethrin and fenvalerate were recognized, while no difference was observed for fenitrothion. In the Miyakonojo colony, however, no difference in $\mathrm{LD}_{50}$ values between the two genotypes was observed for the three insecticides tested. The $\mathrm{KT}_{50}$ values and the mortalities of backcrossed progeny showed a similar tendency 
Table 7. Susceptibility of backcrossed progeny of housefly (resistant strain or colony $++\times F_{1}$ progeny $+\mid B x^{2}$ 占) to pyrethroids by $1 \%$ oil spray method

\begin{tabular}{|c|c|c|c|c|c|}
\hline \multirow{2}{*}{ Insecticide } & \multirow{2}{*}{$\begin{array}{l}\text { Genotype } \\
\text { of III } \\
\text { chromosome }\end{array}$} & \multicolumn{2}{|c|}{$\mathrm{KT}_{50}(\min )$} & \multicolumn{2}{|c|}{ Mortality $(\%)^{\mathrm{a}}$} \\
\hline & & $228_{\Theta 2 b}$ & Miyakonojo & $228_{\Theta 2 b}$ & Miyakonojo \\
\hline \multirow[t]{2}{*}{ Permethrin } & $+1+$ & $>15$ & 5.1 & 50 & 100 \\
\hline & $+\mid B x^{2}$ & 5.0 & 4.0 & 100 & 100 \\
\hline \multirow[t]{2}{*}{ Fenvalerate } & $+1+$ & $>15$ & 7.1 & 30 & 100 \\
\hline & $+\mid B x^{2}$ & 4.4 & 4.0 & 93 & 100 \\
\hline \multirow[t]{2}{*}{ Tetramethrin } & $+1+$ & $>15$ & 1.2 & 2.6 & 10 \\
\hline & $+\mid B x^{2}$ & 1.3 & 0.89 & 10 & 12 \\
\hline
\end{tabular}

a Mortality after $24 \mathrm{hr}$ for all houseflies tested.

to the results obtained by topical application method (Table 7).

\section{DISCUSSION}

The $228_{\mathrm{e} 2 \mathrm{~b}}$ strain possessed a high level of resistance to pyrethroids in both knockdown and lethal activities (Tables 1 and 2). It has been reported that this strain has a major recessive resistance factor associated with nerve insensitivity for permethrin on the third chromosome, and that no other resistant factors are found (AHN et al., 1986 a, b). The Miyakonojo colony, however, showed a moderate level of resistance to pyrethroids and fenitrothion, and the factors conferring resistance to permethrin in this colony with selection by permethrin were found on autosomes 2,3 and 5 (TAKADA et al., 1988).

In this paper, we investigated the contribution of the recessive factor on the third chromosome for the resistance in $228_{\mathrm{e} 2 \mathrm{~b}}$ strain and Miyakonojo colony without selection using the dominance marker " $B x^{2}$ " on the third chromosome, because this gene was independent of the susceptibility to insecticides in both knockdown and lethal activities (Tables 3 and 4 ). In the $228_{\text {e2b }}$ strain, the recessive factor on the third chromosome influenced the resistance to permethrin and fenvalerate (Table 6). In contrast, the contribution of the recessive factor on the third chromosome in the Miyakonojo colony without selection was undetectable. Therefore, it is clear that the two strains differ the contribution of the recessive factor to insecticide-resistance on the third chromosome. The difference in this experiment and in linkage group analysis (TAKADA et al., 1988) is thought to be the result of the change of frequency of the recessive resistance factor on the third chromosome by selection with permethrin. Furthermore, no significant differences in the $\mathrm{LD}_{50}$ values of $B x^{2}$ genotypes of backcrossed progeny to permethrin and fenvalerate were observed between $228_{\mathrm{e} 2 \mathrm{~b}}$ strain and Miyakonojo colony. It is therefore presumed that the two resistant houseflies used in this study would show approximately the same susceptibilities for pyrethroids, respectively, if the recessive resistant factor on the third chromosome were removed.

As shown in Table 7, it is apparent that the resistance factor on the third chromosome in $228_{\mathrm{e} 2 \mathrm{~b}}$ strain influences not only the mortality but also the knockdown time. In the two genotypes in the Miyakonojo colony, there was no difference either in lethal 
activity or knockdown activity.

The genetic method used in this study is considered very simple and useful to determine the importance of the recessive resistance factor on the third chromosome in a population of houseflies.

\section{REFERENCES}

AhN, Y. J., T. Shono and J. Fukami (1986 a) Linkage group analysis of nerve insensitivity in a pyrethroid resistant strain of housefly. Pestic. Biochem. Physiol. 26: 231-237.

Ahn, Y. J., T. Shono and J. FuKami (1986 b) Inheritance of pyrethroid resistance in a housefly strain from Denmark. J. Pesticide Sci. 11: 591-596.

Georghiov, G. P. (1969) Genetics of resistance to insecticides in houseflies and mosquitoes. Exp. Parasitol. 26: $224-255$.

Hiroyoshr, T. (1977) Some new mutants and revised linkage maps of the housefly, Musca domestica L. Japan J. Genetics 52: 275-288.

KeIDing, J. (1976) Development of resistance to pyrethroids in field populations of Danish houseflies. Pestic. Sci. 7: 283-291.

STONE, B. F. (1968) A formula for determining degree of dominance in cases of monofactorial inheritance of resistance to chemicals. Bull. WHO 38: 325-326.

TAKADA, Y., T. Hiroyoshi and M. Hirano (1988) Linkage group analysis of permethrin resistance in the Miyakonojo colony of the housefly, Musca domestica L. (Diptera: Muscidae). Appl. Ent. Zool. 23: $122-126$. 